This item was submitted to Loughborough's Research Repository by the author.

Items in Figshare are protected by copyright, with all rights reserved, unless otherwise indicated.

\title{
Resilience and critical infrastructure: origins, theories and critiques
}

\section{PLEASE CITE THE PUBLISHED VERSION}

https://doi.org/10.1057/978-1-137-53675-4_7

\section{PUBLISHER}

Palgrave Macmillan (c) The Author(s)

\section{VERSION}

AM (Accepted Manuscript)

\section{PUBLISHER STATEMENT}

This book chapter was published in the book The Palgrave Handbook of Security, Risk and Intelligence. The definitive published version is available at https://doi.org/10.1057/978-1-137-53675-4_7.

\section{LICENCE}

CC BY-NC-ND 4.0

\section{REPOSITORY RECORD}

Zebrowski, Chris, and Dan Sage. 2017. "Resilience and Critical Infrastructure: Origins, Theories and Critiques". Loughborough University. https://hdl.handle.net/2134/21565. 


\section{Resilience and Critical Infrastructure: Origins, Theories and Critiques}

\section{Introduction}

On October $13^{\text {th }} 1997$ the Presidential Commission on Critical Infrastructure Protection (PCCIP) published its report to the US government to secure the 'life support systems of our nation' (President's Commission on Critical Infrastructure Protection 1997: 5). Driving the PCCIP was a new threat stemming from the complex interdependencies of US infrastructures. These threats had been tragically in the 1995 bombing of the Alfred P. Murray Federal Building in Oklahoma City and its cascading effects across the normal functioning of US government agencies, including the FBI (Brown 2006). The PCCIP incubated the prioritization of CIP in US polity, spanning; Presidential Directive 63 (1998), Executive Orders 13228 and 13231 and the US Patriot Act (all 2001) (Moteff 2015). And yet, what is perhaps most surprising, especially when viewed over a decade later, is what is absent from these early policies: the legal foundation of CIP contains almost no reference to what is perhaps the most prevalent security discourse in the last decade - resilience. Indeed, the term 'resilience' appears just four times in the 1997 PCCIP report, mostly as a synonym for robustness, and not at all in the Directives and Orders that afford CIP a legal mandate in the US. By contrast, in 2013's Presidential Policy Directive (PPD) 21 - Critical Infrastructure Security and Resilience - the term 'resilience' appears 44 times - broadly defined as the 'ability to prepare for and adapt to changing conditions and withstand and recover rapidly from disruptions' (The White House 2013). 
In response to these shifts towards thinking about CIP and resilience, in this chapter we map the intersection and imbrication of these two objects - critical infrastructure $(\mathrm{CI})$ - and then, resilience - over the last decade or so. In so doing, our purpose is to examine what making critical infrastructure resilient might variously mean, whether to governments, infrastructure operators or diverse publics; and by the same token how has accepting that resilience is infrastructural altered notions of resilience? Our discussions across this chapter draws from two closely related bodies of literature. The first critically examines the political framings of varied notions of resilience (Anderson 2015; Grove 2014; Neocleous 2013; Cooper \& Walker 2011; White \& O'Hare 2014). The second, how infrastructural materialities and circulations mediates certain conditions of life and their political imaginings (Amin 2013; Bennett 2005; Graham 2009; Star 1999; Swyngedouw 2006). In bridging these literatures, we would also like to draw particular attention to how certain notions of resilience, notably those deemed 'neoliberal' are being exposed (Joseph 2013b; Cooper \& Walker 2011), challenged (Amin 2013; Sage et al. forthcoming), even multiplied (Anderson 2015), through their circulation within the materialities of critical infrastructure.

But our chapter goes further than simply reviewing extant debates, it has a more programmatic flavour too - we propose an extension of established interest across political science and human geography in these debates around resilience and infrastructure to a third, as yet disconnected, set of studies: organization theories around the mutual production of organization/disorganization (Clegg et al. 2005; Dale \& Burrell 2011; Stiles 2011; Parker 2011). We contend that the intersection between resilience and infrastructure can be related to theories of the recursive production of organization/disorganization, wherein 'in its most fundamental sense, organization is the appropriation of order out of disorder' and so 'social structures are ordered, organized and made decidable always at the boundary line between 
opposing forces, between inside and outside, good and bad' (Cooper 1986: 327). Specifically, as we elaborate, the intersection of resilience and infrastructure, can also be understood as a dance between organization and disorganization. Consider, for instance, how we might embrace the disorder of an uncertain future by engineering order around certain hardened, highly efficient, sites and robust institutions, allowing others to 'adapt', whatever that might mean; or, how we might choose to disorganize infrastructural organizations, perhaps removing rigid, centralized, even efficient organizational structures and instead develop new ways to organize, or reorganize, perhaps by creating flatter, decentred, modular, even less capitalistic, infrastructural organizations?

Our chapter is structured as follows. First, we discuss the rise of critical infrastructure. Here we briefly trace the origins of CIP in policy discourse, including mapping out definitions of 'infrastructure' and 'critical infrastructure'. We situate these policy discussions in scholarly reflections both upon the politics of infrastructure, including practices of defining critical infrastructure, and especially the 'infrastructural turn' (Graham 2009) that has registered the significance of infrastructural circulations in enabling, and disabling, certain lives and conditions of life. Secondly, we briefly discuss the development of divergent notions of resilience, especially as they animate security policies and governmental institutions. To inform this discussion we draw upon academic discussions around shifting varieties of resilience, and their application in mobilizing diverse political imaginaries and ways of living (Anderson 2015; Coaffee 2013; Coward 2015; Grove 2013). The intersection of CIP and resilience in policy discourse is then mapped out as it emerged in the last decade. The possibilities for an emerging policy discourse of 'Critical Infrastructure Resilience', as given in President Obama's PPD-12, to extend, supplant, even contradict, tenets of CIP, are also considered. Thirdly, moving beyond policy analysis, we examine more specifically the 
organizational responses to the intersection of resilience and infrastructure. Drawing upon a short account of the California energy crisis we discuss the extent to which infrastructure operators have responded to reorganize themselves, and reciprocal infrastructure circulations, and conditions for life, producing new resiliences. We conclude by reflecting upon how we might continue to make sense of the political significance of intersections between infrastructure and resilience by turning to studies of organization.

\section{The Rise of Critical Infrastructure}

What makes an infrastructure critical? Considerable variation exists internationally in what is recognized as 'critical', let alone what exactly is meant by the term 'infrastructure' (Burgess 2007). The term 'infrastructure' arose within $19^{\text {th }}$ century military circles to refer to installations forming the basis of a specific operation. By 1920 its usage had widened to encompass public works, including roads, canals and railways (Dunn Cavelty \& Søby Kristensen 2008a, p.1). In current policy, critical infrastructures tends to be defined negatively as essential services whose interruption or failure would have a severe impact on daily life (Cf. Cabinet Office 2010b: 4; US Department of Homeland Security 2009: 11; Commission of the European Communities 2005: 7). Yet, what constitutes 'daily life' - let alone what is 'essential' to its functioning - is ambiguous. Hence defining critical infrastructures is a political process (Lundborg \& Vaughan-Williams 2014), involving debates around how particular infrastructures enable certain ways of life (Burgess 2007).

Consequently, recent studies have considered how infrastructures, figured as socio-technical assemblages (Amin 2014; McFarlane 2009; 2011), even 'Cyborgs' (Cowan, 2009), both 
enable and disable particular facets of urban life, in what has been dubbed the 'infrastructural turn' (Graham 2009). Attention to differential provision of critical infrastructures have highlighted how deepening political and economic inequalities within major urban metropolises are reflected in and reinforced by the planning of large scale infrastructure politics to accelerate 'splintering urbanisms' (Graham \& Marvin 2001) while others have shown how these processes have increasingly made infrastructures the target of redistributive politics (Amin 2014). Critical infrastructures can thus reflect, reinforce and progress divisions within and between cities or yield new (non-local) connections which reconfigure political, economic and social relations. But infrastructures must not be understood solely as functional objects; they also circulate aesthetic and affective atmospheres, including utopian visions of progress, modernity and freedom. Indeed, terrorist targeting of infrastructure is symbolic as well as functional (Burgess 2007; Coward 2009; Reid 2008).

Identifying the relationship between critical infrastructure protection and ways of life provides us with a preliminary framework for understanding the recent attention afforded to the problem of critical infrastructure protection. If critical infrastructures - including roads, aqueducts and currencies - have long enabled particular ways of life and the targeting of crucial infrastructures has long been an element of military strategy - from the raising of fields, to the poisoning of waterways, to the targeting of infrastructures within strategic bombing campaigns - then what explains the recent attention afforded to critical infrastructure protection?

On the publication of the PCIPP report, critical infrastructure protection was strongly related to the emerging threat of cyber-attacks on governmental and military facilitates whose increasingly reliance on information and communication, within their day to day operations, 
creating new, complex, vulnerabilities (Bonditti 2008; Dunn 2005). In the years to follow, this framework was extended to encompass not simply those communications infrastructures underpinning governmental and military activities, but to the wider economy. The emphasis placed on critical infrastructure protection reflected a growing recognition of contemporary life's reliance on networked forms of infrastructure. Our growing dependence on the 'always on' functioning of these systems is itself meant that the benefits afforded by these networked infrastructures simultaneously created new vulnerabilities (Adey et al. 2011; Dunn Cavelty \& Søby Kristensen 2008b; Cabinet Office 2008b: 249). While much attention has been paid to how the value attached to critical infrastructures in enabling contemporary forms of life (Lobo-Guerrero 2009) has made them symbolic targets for terrorist attack (Burgess 2007; Coward 2009; Reid 2008), it appears that the particular vulnerability associated with critical infrastructure may be associated with the capacity of discrete failures located within one network to rapidly amplify as they cascade within and across interconnected systems (Arsenault \& Sood 2007; Dunn 2005; Amin 2000). ${ }^{\mathrm{i}}$

The complex interactions of interdependent systems are now understood to exacerbate the dangers inherent to highly networked societies. Drawing on systems theory and organizational analysis, Charles Perrow's Normal Accidents (1999) provides a elucidatory touchstone into the prevalence of low-probability, high-impact events, or 'system accidents' (Perrow, 1999). System accidents can be distinguished from the two modes in which technological accidents have historically been conceived and managed. Historically, accidents have been understood either as a result of negligence (mobilizing processes of adjudication to ascribe 'fault') or as a result of statistical regularity (enabling technologies of workplace insurance) (Ewald 1986). Systems accidents instead arise out of the interactive complexity' of tightly-coupled complex socio-technological systems. Within tightly coupled 
systems, discrete failures located within one sub-system can rapidly cascade within and across sub-systems. The complex interaction of multiple, distributed failures may, in turn, give rise to the non-linear emergence of a catastrophic system accident. The accident cannot be geographically localised to enable a declaration of 'responsibility' or 'fault' (Law \& Mol 2002). A system accident is therefore a function of complex interdependence of components in relation, rather than a product of operator error or component malfunction. Efforts to protect critical infrastructures have however been frustrated by the fragmented and incomplete knowledge of the interconnected architecture of these systems. State efforts to map the geographical and topological spread of critical infrastructure systems (Gorman 2005) are often complicated by high levels of private ownership of critical infrastructures in the West (Graham \& Marvin 1996: 135-138). Instead the interconnections within and between critical infrastructures are more often revealed during periods of suspended service, breakdown or emergency (Graham \& Marvin 1996: 50-53; see also Graham 2010: 3; Graham \& Marvin 2001).

The challenge of such system accidents can also be understood through the UK's 2008 Pitt Review. The report was commissioned to undertake a comprehensive review of the 2007 summer floods which resulted in the 'largest loss of essential services since World War II, with almost half a million people without mains water or electricity' (Cabinet Office 2008b: ix). Throughout the report the particular danger of large-scale flooding is associated with 'cascading effects' (Cabinet Office 2008b: 238, 250-251) that allowed failures located in one system to quickly spread through interdependent 'systems of systems' resulting in interruptions to essential services including power supplies, transport links, telecommunications, and mains water supply (Cabinet Office 2008b: 3). In Longlevens, Gloucestershire, for example, flooding disrupted the power supply of pumping stations 
depended on for flood response (Cabinet Office 2008b: 250) severely compounding the event's devastating effects.

The particular danger associated with critical infrastructures is routinely attributed to an increasingly complex and interdependent world (Cabinet Office 2008a; 2010a) wherein dangers may rapidly amplify and spread across systems of systems through unpredictable processes of complex emergence. The contemporary emergency thus arises from within the very same infrastructures constructed to promote and protect contemporary ways of life. While openness and connectivity may be a source of dynamism it may, at the same time, be that which radically endangers us. 'Resilience' has emerged as a security solution to this particular security problematic. If dangers cannot be sufficiently predicted or protected against, then security must instead turn to mitigating their destructive potential. Resilience promises to mitigate one's exposure to the risks inherent within irreducibly unpredictable and insecure environments by enhancing the capacity to restore systemic functioning quickly and efficiently in the wake of a perturbation. Danger is recast as an opportunity for growth (Richardson 2002; Gunderson \& Holling 2002; Pelling 2011): inciting, and exercising, processes of positive adaption and self-transformation. Resilience strategies therefore aim at the production of systems capable of living-with, or even embracing (Baker \& Simon 2002), risk. Thus, in this sense, the rise of contemporary infrastructures is concomitant with many notions of resilience. Following on from this possibility, in the next section we examine more fully the development of resilience thinking and its relationship to critical infrastructures.

\section{Resilient Critical Infrastructures}


Resilience has emerged as a term of art across a wide range of academic disciplines and practical applications similarly concerned with the need to provide security within environments marked by radical contingency. Resilience has been advanced as a solution to an astonishingly diverse set of problems including, but not limited to, at psychological health (Challen 2009; Clarke et al. 2010), Islamic radicalization (Government of Canada 2011; Weine et al. 2013), economic development (International Monetary Fund 2010; World Resources Institute 2008), climate change (Pelling 2011; DEFRA 2011) and post-traumatic stress disorder (Howell 2012; O’Malley 2010). At their most general level, resilience strategies promise to enhance the capacity to 'bounce-back' from a diverse range of threats from the potentially catastrophic (terrorist attacks, financial collapse) to the relatively mundane (floods, industrial disputes). However, upon closer inspection it is clear the meaning of resilience varies considerably across academic and practitioner fields (Anderson, 2015). Given the diverse range of expertise drawn upon to inform practices of critical infrastructure protection, we should remain suspicious of any singular definition of critical infrastructure resilience. It is beyond the purposes of this chapter to provide an exhaustive account of the different ways in which resilience is understood in CIP discourses. Instead, this chapter will instead explore how the multiple resiliences enacted within efforts to build critical infrastructure resilience equip us with insight into the way efforts to enhance CI resilience are organized. In this section we will begin by reviewing academic literature on resilience before returning to examine how resilience is understood and applied in the context of critical infrastructure protection.

Unlike threat-based security initiatives, which require extensive intelligence to target enemies and eliminate threats, resilience does not require a deep understanding of the nature of threats: when, where, how and why a threat is set to manifest. Resilience is instead 
circumscribed to a risk-based understanding of security which, like insurance, places priority on mitigating vulnerability to events rather than eliminating threats themselves (Aradau et al. 2008: 148). This requires an extensive knowledge of the vulnerabilities of security referents as well as the conditions underpinning their capacity to withstand, absorb and bounce-back from a perturbation. In particular, resilience initiatives have been promoted to respond to the high-impact/low-probability events which evade actuarial capture and strain actuarial-based technologies of risk management such as insurance (Daase and Kessler, 2007, Ericson and Doyle, 2004, Massumi, 2009). As with similar anticipatory logics of security including precaution (Aradau and Munster, 2007, Ewald, 2002, Massumi, 2005b), preparedness (Aradau, 2010, Collier, 2008, Lakoff, 2007, Collier and Lakoff, 2008a) and pre-emption (Cooper, 2006a, de Goede, 2008b, de Goede and Randalls, 2009), the value of resilience is tied to the promise of providing certainty and security in a world in which threats cannot be entirely known or predicted (Zebrowski 2015).

The contemporary idea of resilience is a product of multiple, overlapping genealogies which can be traced to developments in ecological science (Holling 1973), child psychology (Werner \& Smith 1989; Garmezy 1974) and neoliberal economics (Cooper \& Walker 2011; Zebrowski 2013). While we should therefore be suspicious of any singular claim as to the origin of resilience, the focus within resilience research on C.S. Holling's Resilience and Stability of Ecological Systems (Holling 1973) provides a rich theoretical starting place for understanding the implications of resilience for critical infrastructure initiatives. The purpose of Holling's article was to outline a novel approach to ecosystem management rooted in the idea of resilience. A resilience-based approach, according to Holling, diverged markedly from the equilibrium-based approaches to ecosystem management. Rather than focusing on rapidly returning a system to a stable maximum (or equilibrium point) following a 
perturbation, a resilience approach would seek to enhance the "conditions for persistence" (1973: 2) which underpin an ecosystem's integrity in the face of large-scale disturbances. ${ }^{1}$ Resilience was defined as "a measure of the persistence of systems and of their ability to absorb change and disturbance and still maintain the same relationships between populations or state variables" (1973: 14).

Holling's argument is driven by an important reconceptualization of the nature of ecosystems. Holling took issue with the cybernetic science informing predominant approach to ecosystem management, such as Maximum Sustained Yield (MSY). Drawing on developments in third-wave cybernetics associated with chaos, complexity and selforganizing autopoietic systems, Holling rooted his idea of ecological resilience in an understanding of ecosystems as complex adaptive systems. Complex adaptive systems are characterised by capacities to self-organize and evolve through non-linear processes. The security afforded to complex adaptive systems is not measured by its capacity to persist unchanged through a period of crisis. On the contrary, the security of the system is premised on its capacity to incite processes of adaptive evolution in response to changes detected in its environmental milieu. Anticipating later developments in business enterprises (Castells 1996; Boltanski \& Chiapello 2007) and militaries (Dillon \& Reid 2009; Duffield 2002; Arquilla \& Ronfeldt 1997) towards dynamic 'network'-based forms of organization, Holling's definition of resilience would capture significant transformations in the ways in which security and organization were to be refigured in the years to follow. With resilience, security is no longer a conservative enterprise involving stasis and protection, but an opportunity to change, grow and evolve. Security, understood in terms of resilience, demands the persistent

\footnotetext{
${ }^{1}$ In his later work Holling would more refer to these cyberntically informed models of ecosystemic governance as 'engineering resilience' in contrast to his complexity informed approach which we would call 'ecosystems resilience' (Holling 1996)
} 
reorganization of organizational form to mitigate one's risks and capitalize on emerging opportunities.

Resilience thus provides a security solution for 'open' complex adaptive systems. The danger, according to Holling, of applying protectionist policies of ecosystems management to open, complex adaptive systems was that they can in fact be counter-productive. By protecting select species from their predators, such policies may in fact be generating high levels of dependency, inadvertently eroding the resilience of a system and leaving it more susceptible to even minor external perturbations (1973: 9). By potentially incubating the ecological conditions for the socio-technical 'system accidents' described by Perrow (1999) conservationist policies such as Maximum Sustainable Yield could thus inadvertently be amplifying the very conditions of insecurity they were seeking to eradicate. A resilience approach, by contrast, is premised on maintaining the openness of a system: allowing small changes detected in a system's environmental milieu to trigger processes of self-organization. Governance, rather than imposing security, would be directed towards enhancing a systems natural adaptive capacity.

In more recent moves to extend this ecological framework to urban systems (conceived of as socio-technical systems) critical infrastructures are recognized as an important element underpinning adaptive capacity (Öberg et al. 2014; Nelson et al. 2010). The relationship between critical infrastructures and resilience is two-fold. On the one hand, critical infrastructures are often essential to the resilience of broader systems. Telecommunications 
infrastructures, for example, have been recognized as 'fundamental enablers' ${ }^{2}$ of resilience underpinning a wide assortment of activities from ensuring the continuity of economic processes to the organization of rescue operations in the wake of a disaster. On the other hand, given the important role critical infrastructures often play in underpinning resilience, they must themselves be made resilient. In the case of telecommunications networks, this can involve investing in built-in redundancies and layered back-up solutions such as satellite communications. However this may also raise a number of questions. Is the resilience exhibited in these two respects referring to the same thing? Can particular infrastructure developments close down certain adaptive possibilities while opening others? Might they open adaptive possibilities for some forms of life while foreclosing those of others?

The outline of ecological resilience advanced by Holling is premised on a deep problematization of protectionist logics of security. Its clear resonance with neoliberal critiques of the Welfare State have, in turn, not been overlooked by critical resilience scholars (Cooper \& Walker 2011; Zebrowski 2013). Yet, the claims that resilience represents a pernicious neoliberal ideology of entrepreneurial responsibilization and individualization (O'Malley, 2010; Neocleous 2013; Evans \& Reid 2014) may in fact overgeneralize themselves: making neoliberalism a master signifier through which the true essence of resilience can be deciphered. This is especially problematic in the field of critical infrastructure protection where much (though not all) of what is conducted under label 'critical infrastructure resilience' appears to conform more closely to Holling's definition of engineering resilience and the logic of centralized protection, than with more 'postmodern'

\footnotetext{
${ }^{2}$ Cabinet Office, 'Resilient Communications' Gov.uk website, https://www.gov.uk/resilient-communications accessed 6 February 2015
} 
notions of ecological resilience. ${ }^{3}$ Hence, rather than accepting neoliberalism as a completed framework, through which resilience, singular, can be understood in the field of critical infrastructure protection, what is required is a way of developing a critically minded understanding of how multiple (critical) infrastructures and resiliences are organized, spatially, temporally and economically. To this end, in the final section of this paper we draw upon recent work in organization studies, alongside an empirical vignette, to develop one possibility for framing such a task.

\section{Organizing Infrastructures and Resiliences: Californian Energy Markets}

Our preference for the term 'organization' in this final section is not insignificant. Starting with the concept of organization as drawn in organizational theory, where it is taken as both noun and verb (Cooper 1986; Law 1994), in this final section we map out an alternative, lessoften trodden, path for critically-minded empirical analyses of the intersection of resilience and infrastructure. Specifically we wish to examine how multiple forms of resilience and infrastructure emerge, interact and transform each other. To develop our discussion we introduce an empirical account concerning an organizational attempt to improve the resilience of a piece of critical infrastructure - an electricity network. Our story is both one of organizations, public and private, and also of organizing - the attempt to create an energy network, a critical infrastructure, that could be isolated from its unpredictable environment, whether unaffordable consumer prices or weather events. 
We begin our story with a piece of legislation - Assembly Bill 1890 - approved by Pete Wilson, Governor of California, on the $23^{\text {rd }}$ September 1996. This bill was created to restructure the electricity market in the state of California. The changes were intended to reduce California's high electricity prices as well as enhance the reliability of the California electricity system which had been subject to a series of high profile outages. Located within an area famed for its seismic activity, wild fires and high temperatures, and reliant upon the importation of energy generated across the Western States, California's electricity network had long experienced various shocks. The solution offered by AD1890, and supported by Federal policy, was to secure longer-term investment and network reliability by increasing market competition among power companies. This involved dismantling the monopoly position of three large energy generating and supply companies in California. Two independent, non-profit, state chartered companies were to be created, one tasked with managing the reliable distribution of electricity (CISO) and another running a 'spot market' (CPX) through which companies generating electricity and those selling it to customers could bid for supply agreements for the next day. Customers would be protected from price rises through price controls until the energy companies divested their generating capacity. The reliability to ensure demand was met was legally the responsibility of both CPX ensuring utility generated companies bided for all energy demanded in California and the CISO ensuring investment in the distribution network and maintaining reserve supplies. This more competitive market-based organisation of energy was deemed more reliable than the previous market monopolistic one which was said to stifle network investment and had failed to respond adequately for growing electricity demand. California's future looked bright. However by early 2001 the plan failed dramatically: in areas where retail prices were not controlled they rose dramatically, no new power plants had been built in a decade despite increasing demand, and then California suffered a series of rolling blackouts over several 
months. Eventually the state government was forced to sign long contracts to purchase billions of dollars of power outside the CPX to ensure that future demand could be met, while the federal regulator approved wholesale price controls during high demand periods (for more see McLean \& Elkind 2004; Weare 2003).

If it is used at all to discuss resiliency and infrastructure, this crisis tends to be associated with the poor resiliency of California's market-led, and under-invested, electricity infrastructure (Congressional Budget Office 2001; Weare 2003). That is, the ability of a network of generating plants, transmission cables, power supply companies, traders and retailers, as well the operations of the CPS and CISO to deliver a reliable supply to meet the needs of the Californian people, despite a trivial, and entirely foreseeable, external shock. In the case of California the shock was the lack of electricity from hydroelectric power in the Western States after the dry winters of 2000 and 2001(Weare 2003). Understood through the rubric of CIP, as 2001 approached this vital, if complex, piece of infrastructure possessed low resilience. But this is also a story of poor organization too. Organizational theories, from transaction cost economics to neo-institutionalism, suggests that organizing can be defined as the reduction of environmental complexity, not least that of 'the market' (Santos \& Eisenhardt 2005; Schreyögg \& Sydow 2010). In California in 2000/1, the CISO and CPX and the energy retailers could not organize well, they could not reduce or manage the complexity of the energy market, rather they were driven by it; and indeed in 2001 many Californian power companies filed for bankruptcy. Put in this way, this critical infrastructure was not resilient because it was organized around a dysfunctional, or disorganizing, market: a range of organizations, from the state government to energy retailers and customer organizations 
(from schools to businesses), were pulled into the abyss of a market where power retailers were forced to buy energy high at wholesale and sell cheap to consumers, dissuading technological investment and eventually preventing them from purchasing sufficient electricity to cope with a trivial shock. In other words, all these actors were complicit in organizing a disorganizing energy infrastructure, as they created a certain market inside the critical infrastructure of energy supply. Here the contradictory spacings and timings between two interdependent systems, allowed the volatile transmission of money to impede the stable flow of electrons. This 'disorganized market' thesis has been rehearsed across many studies (e.g. Bushnell 2004; Congressional Budget Office 2001; McLean \& Elkind 2004; Weare 2003). And thus, once the California government stepped in to create a more monopolistic market, once the spacings and timings of money flows and electron flows were better harmonized, the resiliency of California's electricity infrastructure increased - most organizations involved were now more able to control their market environment by purchasing and selling power on longer-term contracts so as to hedge themselves against future shocks.

There is, however, an alternative reading of the crisis - we might retell this story to consider the resilience of power trading and supply companies, companies like Enron Corporation. It is now well-known how Enron, and others, 'gamed' the California energy market to generate profit (McLean \& Elkind 2004). A variety of mechanisms were created with headline grabbing names such as 'fat boy' and 'death star' that artificially reduced supply during the rolling blackouts so as to inflate wholesale prices. Perhaps the most insidious of these mechanisms were instructions given by Enron to power companies (including some they owned) to turn off a power plant in Nevada during California's rolling blackouts for erroneous maintenance reasons in order to artificially inflate wholesale prices on the CPX 
(Borger 2005). In this counter-narrative, the systemic complexities within California's energy infrastructure, from its overreliance upon out of state power and its intricate market rules and complex chains of organizations, was attractive to Enron's ruthlessly short-term profitorientated executives (McLean \& Elkind 2004). For Enron, the timing of the crisis could not have been better: it had suffered from a series of setbacks, including disappointing results from its expansion into broadband and various badly performing global projects - the Californian crisis helped the organisation weather these shocks. Viewed in this way, the systemic complexity of California's energy infrastructure, its complex interdependences between different organizational actors, aided the resilience of their organization. In other words, in Enron, resilience equated not to the protection of its physical assets per se, but to its capacity for organizational adaptations to an otherwise potentially unstable situation. After all, we might expect that a power company could only thrive on the reliable supply of power to its customers. And yet, in this case the same unstable energy market that reduced the resiliency of communities in California, and the energy retailers, to weather certain shocks, aided the profit-based resilience of power supply and trading firms. Indeed, Enron and other companies repeatedly campaigned against the introduction of regulations, such as price controls, intended to stabilize' California's market-based energy infrastructure (McLean \& Elkind 2004). When eventually the state of California challenged the market in 2001, they removed one of Enron's abilities to influence its environment just as the corporation started its now infamous fall into bankruptcy and scandal.

\section{Concluding comments}


In ending with this double reading of the California energy crisis we have sought to illustrate how by paying attention to organizations and acts of organizing we can better examine how different notions of resiliency and indeed infrastructure interact with each other. Despite its current distance from these critical debates around resilience, organization studies can usefully help us elaborate the central issue that we started this chapter: what does it mean to make infrastructure resilient and how does accepting that resilience is infrastructural alter wider notions of resilience. These questions are readily being asked and answered through acts of organizing and through the practices of organizational actors, not least through the creation of certain market devices. More specifically, the organization of one notion of resiliency, and the resiliency of one notion of organizing, can be shown to require the disorganization of other organizations, infrastructures and resiliences. Enron, and other companies, constructed a short-term competitive notion of adaptive resilience where energy infrastructures could become financial infrastructures, helping Enron mitigate shocks elsewhere in its business. But this organization of resilience and infrastructure worked against protectionist nostrums of CIP: it cut off the electricity of people who in turn were unable to work, attend school or shop for groceries (McLean \& Elkind 2004). Likewise, when this market was reformed again, it involved disorganizing Enron's financial-energy infrastructure, introducing a different version of resilience through a different set of infrastructures. This account thus resonates with theories around the mutual dependency of organization and disorganization (e.g. Cooper 1986; Latour 2013) to help articulate the multiplicity and complexity of enactments of resilience (e.g. Knox et al. 2015). Indeed, as Cooper describes it, the ordering force of organization "necessarily requires the "support" of an "inferior" position [disorder] inasmuch as the latter is what defines the former" (1986: 328). Put differently, as Knox et al. explain, in their organizational analysis of airport disruptions: 'Whatever is construed as dis-organization, in-security and dis-order cannot, it seems, be eradicated but 
rather becomes the object of ongoing labours of deferral and differal. Order and disorder, organization and disorganization, are the making, as well as the unmaking, of each other' (2015: 1015).

The Californian energy crises also suggests the critical role played by a range of organizational actors in producing particular notions of resilience. In our account, the insertion of the CISO, CPX and Enron into the milieu of California's energy infrastructure, transformed and multiplied understandings of resilience and even infrastructure. The complexity of organizations and organizational practices involved in operating, regulating and owning infrastructures is only gestured in our narrative, but is we contend deserving of more critical attention. Taking such organizational analysis further we might consider the organizational cultures and practices within these places of work, not least Enron's venal macho-capitalism where short-term profits were prioritized over and above long-term market sustainability, even if ultimately sowing the seeds of Enron's demise (Levine 2005; Stein \& Pinto 2011). Such organizational norms transformed how the resiliency California's electricity network was constructed. Organizational analysis along these lines reverses the thrust of mainstream business contingency planning (e.g. Cerullo \& Cerullo 2004) to consider how organizational practices, influence, rather than are themselves influenced by, infrastructural resiliency; thus opening up new registers of intervention into CIP. Finally, this story also draws attention to how markets are organized to enact certain conditions of life, and their attendant resiliences and infrastructures. This is an important theme to consider as more and more infrastructures are privatized (Graham \& Marvin 2001) and organized around specific market logics. Indeed, while the term 'neoliberal' is widely applied to diagnose current practices around resiliency and infrastructure (e.g. Cooper \& Walker 2011; Joseph 2013a; Neocleous 2013; White \& O’Hare 2014), consideration of what sort of markets are 
being constructed through what infrastructures, with what asymmetries of agency, and with what effects remains missing in critical analysis on resilience and critical infrastructure. What is more, in the case of California, the material topography of the state's energy infrastructure (i.e. its dependency on out of state power) helped disorganize one notion of resiliency while organizing another. Although typically the term 'neoliberalism' or 'market' is used in a singular form in debates around resiliency and infrastructure, introducing critically-minded organizational analysis along these lines might help us register the complex multiplicity of market devices, and associated resiliences and infrastructures. Future work could usefully benefit from Michel Callon's anthropologies of the performativity and multiplicity of markets (e.g. Callon 1998; Callon \& Muniesa 2005; Muniesa et al. 2007), where 'The market is no longer that cold, implacable and impersonal monster which imposes its laws and procedures while extending them ever further. It is a many-sided, diversified, evolving device which the social sciences as well as the actors themselves contribute to reconfigure' (Callon 1998: 51). In short, the multidisciplinary field of organization studies has much to offer understandings of the political complexities and multiplicities around the imbrication of critical infrastructures and resiliences.

\section{References}

Adey, P., Anderson, B. \& Lobo-Guerrero, L., 2011. An ash cloud, airspace and environmental threat. Transactions of the Institute of British Geographers, 36(3), pp.338-343.

Amin, A., 2014. Lively Infrastructure. Theory, Culture \& Society, 31(7-8), pp.137-161. 
Amin, A., 2013. Surviving the turbulent future. Environment and Planning D: Society and Space, 31(1), pp.140-156.

Amin, M., 2000. Towards self-healing infrastructure systems. IEEE Computer, 33(8), pp.4453.

Anderson, B., 2015. What Kind Of Thing Is Resilience? Politics, 35(1), pp.60-66.

Aradau, C., Lobo-Guerrero, L. \& van Munster, R., 2008. Security, Technologies of Risk, and the Political: Guest Editor's Introduction. Security Dialogue, 39(2-3), pp.147-154.

Arquilla, J. \& Ronfeldt, D., 1997. In Athena's Camp: Preparing for Conflict in the Information Age, Santa Monica: RAND.

Arsenault, D. \& Sood, A., 2007. Resilience: A System Design Imperative. In Critical Thinking: Moving from Infrastructure Protection to Infrastructure Resilience. Washington, D.C.: George Mason University, pp. 87-96.

Baker, T. \& Simon, J., 2002. Embracing Risk: The Changing Culture of Insurance and Responsibility, Chicago: University of Chicago Press.

Bennett, J., 2005. The Agency of Assemblages and the North American Blackout. Public Culture, 17(3), pp.445-465.

Boltanski, L. \& Chiapello, E., 2007. The New Spirit of Capitalism, London: Verso.

Bonditti, P., 2008. Homeland security though tracebility: Technologies of control as critical infrastructures. In M. Dunn Cavelty \& K. Søby Kristensen, eds. Securing the Homeland: Critical infrastructure, risk and (in)security. Milton Park: Routledge, pp. 130-152.

Borger, J., 2005. Tapes reveal Enron's secret role in California's power blackouts. The Guardian.

Brown, K.A., 2006. Critical Path: A Brief History of Critical Infrastructure Protection in the United States, Fairfa, VA: Spectrum Publishing Group, Inc.

Burgess, J.P., 2007. Social Values and Material Threat: the European Programme for Critical Infrastructure Protection. Int. J. Critical Infrastructures, 3(3/4), pp.471-487.

Bushnell, J., 2004. California's electricity crisis: a market apart? Energy Policy, 32(9), pp.1045-1052.

Cabinet Office, 2010a. A Strong Britain in an Age of Uncertainty: The National Security Strategy, London: HM Government.

Cabinet Office, 2010b. Sector Resilience Plan for Critical Infrastructure 2010, London: HM Government.

Cabinet Office, 2008a. The National Security Strategy of the United Kingdom: Security in an Interdependent World, London: HM Government. 
Cabinet Office, 2008b. The Pitt Review - Learning Lessons from the 2007 Floods, London: HM Government.

Callon, M., 1998. Introduction: The embeddednes of economic markets in economics. The Sociological Review, 46(s1), pp.1-58.

Callon, M. \& Muniesa, F., 2005. Peripheral Vision: Economic Markets as Calculative Collective Devices. Organization Studies, 26(8), pp.1229-1250.

Castells, M., 1996. The Rise of the Network Society, Oxford: Blackwell.

Cerullo, V. \& Cerullo, M.J., 2004. Business Continuity Planning: A Comprehensive Approach. Information Systems Management, 21(3), pp.70-78.

Challen, A., 2009. UK Resilience Programme evaluation : interim report, London: London School of Economics.

Clarke, J., Barlow, C. \& Nicholson, J., 2010. Resilience: Bounce Back from Whatever Life Throws at You, Richmond: Crimson Publishing Limited.

Clegg, S.R., Kornberger, M. \& Rhodes, C., 2005. Learning/Becoming/Organizing. Organization, 12(2), pp.147-167.

Coaffee, J., 2013. Rescaling and Responsibilising the Politics of Urban Resilience: From National Security to Local Place-Making. Politics, 33(4), pp.240-252.

Commission of the European Communities, 2005. Green Paper: On a European Programme for Critical Infrastructure Protection.

Congressional Budget Office, 2001. Causes and lessons of the California electricity crisis, Washington, D.C.

Cooper, M. \& Walker, J., 2011. Genealogies of Resilience: From Systems Ecology to the Political Economy of Crisis Adaptation. Security Dialogue, 14(2), pp.143-160.

Cooper, R., 1986. Organization/Disorganization. Social Science Information, 25(2), pp.299335.

Coward, M., 2015. Hot Spots/Cold Spots: Infrastructural Politics in the Urban Age. International Political Sociology, 9(1), pp.96-99.

Coward, M., 2009. Network Centric Violence, Critical Infrastructure and the Urbanization of Security. Security Dialogue, 40(4-5), pp.399-418.

Dale, K. \& Burrell, G., 2011. Disturbing structure: Reading the ruins. Culture and Organization, 17(2), pp.107-121.

DEFRA, 2011. Climate Resilient Infrastructure: Preparing for a Changing Climate. 
Dillon, M. \& Reid, J., 2009. The Liberal Way of War: Killing to Make Life Live, Milton Park: Routledge.

Duffield, M., 2002. War as a Network Exercise: The New Security Terrain and its Implications. Cultural Values: The Journal for Cultural Research, 6(1\&2), pp.153-166.

Dunn Cavelty, M. \& Søby Kristensen, K., 2008a. Introduction. In M. Dunn Cavelty \& K. Søby Kristensen, eds. Securing "the Homeland”: Critical Infrastructure, Risk and (In) security. London and New York: Routledge, pp. 1-14.

Dunn Cavelty, M. \& Søby Kristensen, K., 2008b. Securing the "Homeland": Critical Infrastructure, Risk and (In)security. Critical Studies in Security and International Relations.

Dunn, M., 2005. The socio-political dimensions of critical information infrastructure protection (CIIP). International Journal of Critical Infrastructures, 1(2/3), pp.258-268.

Evans, B. \& Reid, J., 2014. Resilient Life: The Art of Living Dangerously, Polity Press.

Ewald, F., 1986. L'État Providence, Paris: Bernard Grasset.

Garmezy, N., 1974. The study of competance in children at risk for severe psychopathology. In E. J. Anthony \& C. Koupernik, eds. The child in his family: Children at psychiatric risk:III. New York: Wiley, p. 547.

Gorman, S.P., 2005. Networks, Security and Complexity: The role of public policy in critical infrastructure protection, Cheltenham: Edward Elgar Publishing Ltd.

Government of Canada, 2011. Building Resilience Against Terrorism: Canada's CounterTerrorism Strategy,

Graham, S., 2010. Cities Under Siege: The New Military Urbanism, London \& New York: Verso.

Graham, S. ed., 2009. Disrupted Cities: When Infrastructure Fails, London \& New York: Routledge.

Graham, S. \& Marvin, S., 2001. Splintering Urbanism: Networked Infrastructures, Technological Mobility and the Urban Condition, London: Routledge.

Graham, S. \& Marvin, S., 1996. Telecommunications and the City: Electronic Spaces, Urban Places, London \& New York: Routledge.

Grove, K., 2014. Agency, affect, and the immunological politics of disaster resilience. Environment and Planning D: Society and Space, 32(December 2009).

Grove, K., 2013. Hidden transcripts of resilience: power and politics in Jamaican disaster management. Resilience: International Policies, Practices and Discourses, 1(3), pp.193-209. 
Gunderson, L.H. \& Holling, C.S., 2002. Panarchy : understanding transformations in human and natural systems, Washington, DC: Island Press.

Holling, C.S., 1996. Engineering resilience versus ecological resilience. In P. Schulze, ed. Engineering within ecological constraints. Washington, D.C.: National Academy Press, pp. 31-44.

Holling, C.S., 1973. Resilience and Stability of Ecological Systems. Annual Review of Ecology and Systematics, 4, pp.1-23.

Howell, A., 2012. The Demise of PTSD: From Governing through Trauma to Governing Resilience. Alternatives: Global, Local, Political, 37(3), pp.214-226.

International Monetary Fund, 2010. Regional economic outlook : Sub-Saharan Africa : resilience and risks.

Joseph, J., 2013a. Resilience as embedded neoliberalism : a governmentality approach. Resilience: International Policies, Practices and Discourses, 1(1), pp.37-41.

Joseph, J., 2013b. Resilience in UK and French Security Strategy: An Anglo-Saxon Bias? Politics.

Knox, H. et al., 2015. Something happened: Spectres of organization/disorganization at the airport. Human Relations, 68(6), pp.1001-1020.

Latour, B., 2013. An Inquiry into Modes of Existence: An Anthropology of The Moderns, Cambridge, MA: Harvard University.

Law, J., 1994. Organizing Modernity, Offord: Blackwell Publishers.

Law, J. \& Mol, A., 2002. Local entanglements or utopian moves: an inquiry into train accidents. In M. Parker, ed. Utopia and Organization. Oxford: Blackwell Publishing, pp. 82-105.

Levine, D.P., 2005. The corrupt organization. Human Relations, 58(6), pp.723-740.

Lobo-Guerrero, L., 2009. Infrastructure as Strategized Space: Critical Infrastructure Protection and the Biopolitics of Heterotopia and Circulation, Paper presented at Keele University, "Biopolitics of Values" Workshop, 19-20th January 2010.

Lundborg, T. \& Vaughan-Williams, N., 2014. New Materialisms, discourse analysis, and International Relations: a radical intertextual approach. Review of International Studies, pp.1-23.

McFarlane, C., 2011. The city as assemblage: Dwelling and urban space. Environment and Planning D: Society and Space, 29(4), pp.649-671.

McFarlane, C., 2009. Translocal assemblages: Space, power and social movements. Geoforum, 40(4), pp.561-567. 
McLean, B. and \& Elkind, P., 2004. The Smartest Guys in the Room, New York: Penguin.

Moteff, J.D., 2015. Critical Infrastructures: Background, Policy, and Implementation, Washington, D.C.

Muniesa, F., Millo, Y. \& Callon, M., 2007. An introduction to market devices. Sociological Review, 55(s2), pp.1-12.

Nelson, M.C. et al., 2010. The cross-scale interplay between social and biophysical context and the vulnerability of irrigation-dependent societies: Archaeology's longterm perspective. Ecology and Society, 15(3).

Neocleous, M., 2013. Resisting Resilience. Radical Philosophy, 178(March/April), pp.2-7.

O’Malley, P., 2010. Resilient Subjects: Uncertainty, Warfare and Liberalism. Economy and Society, 39(4), pp.488-509.

Öberg, G. et al., 2014. The notion of sewage as waste: A study of infrastructure change and institutional inertia in Buenos Aires, Argentina and Vancouver, Canada. Ecology and Society, 19(2).

Parker, M., 2011. Organizing the Circus: The Engineering of Miracles. Organization Studies, 32(4), pp.555-569.

Pelling, M., 2011. Adaptation to Climate Change: From Resilience to Transformation, London \& New York: Routledge.

Perrow, C., 1999. Normal Accidents: living with high-risk technologies, Princeton: Princeton University Press.

President's Commission on Critical Infrastructure Protection, 1997. Critical Foundations: Protecting America's Infrastructures, Washington, DC.

Reid, J., 2008. Conclusion: The biopolitics of critical infrastructure protection. In M. Dunn Cavelty \& K. Søby Kristensen, eds. Securing "the Homeland”: Critical Infrastructure, risk and (in)security. London and New York: Routledge, pp. 176-183.

Richardson, G.E., 2002. The Metatheory of Risk and Resiliency. Journal of Clinical Psychology, 58(3), pp.307-321.

Sage, D., Fussey, P. \& Dainty, A., Securing and Scaling Resilient Futures: Neoliberalization, Infrastructure and Topologies of Power. Environment and Planning D: Society and Space.

Santos, F.M. \& Eisenhardt, K.M., 2005. Organizational Boundaries and Theories of Organization. Organizational Science, 16(5), pp.491-508.

Schreyögg, G. \& Sydow, J., 2010. CROSSROADS--Organizing for Fluidity? Dilemmas of New Organizational Forms. Organization Science, 21(6), pp.1251-1262. 
Star, S.L., 1999. The Ethnography of Infrastructure. American Behavioral Scientist, 43(3), pp.377-391.

Stein, M. \& Pinto, J., 2011. The dark side of groups: A “gang at work" in enron. Group \& Organization Management, 36(6), pp.692-721.

Stiles, D.R., 2011. Disorganization, disidentification and ideological fragmentation: Verbal and pictorial evidence from a British business school. Culture and Organization, 17(1), pp.5-30.

Swyngedouw, E., 2006. Circulations and metabolisms: (Hybrid) Natures and (Cyborg) cities. Science as Culture, 15(2), pp.105-121.

The White House, 2013. Presidential Policy Directive -- Critical Infrastructure Security and Resilience, Washington, D.C.

US Department of Homeland Security, 2009. National Infrastructure Protection Plan: Partnering to enhance protection and resiliency, Washington D.C.

Weare, C., 2003. The California Electricity Crisis: Causes and Policy Options, San Francisco, CA: Public Policy Institute.

Weine, S. et al., 2013. Building Community Resilience to Counter Violent Extremism. Democracy and Security, 9(4), pp.327-333.

Werner, E. \& Smith, R., 1989. Vulnerable but Invincible: A Longitudinal Study of Resilient Children and Youth, New York: Adams, Bannister, and Cox.

White, I. \& O'Hare, P., 2014. From rehetoric to reality: which resilience, why resilience, and whose resilience in spatial planning? Environment and Planning $C$ : Government and Policy, 32(5), pp.934-950.

World Resources Institute, 2008. World Resources 2008: Roots of Resilience--Growing the Wealth of the Poor, Washington D.C.: World Resources Institute (WRI).

Zebrowski, C., 2013. The nature of resilience. Resilience: International Policies, Practices and Discourses, 1(3), pp.159-173.

Zebrowski, C., 2015. The Value of Resilience: Securing Life in the 21st Century, London: Routledge. 